\title{
Meal replacement and functional connectivity in the brain network for appetite: connecting the dots
}

\author{
Tanya Zilberter * \\ Infotonic Conseil, Marseille, France \\ Keywords: meal replacement, appetite, fMRI, obesity, eating behavior
}

\section{A commentary on}

Meal replacement: calming the hot-state brain network of appetite. by Paolini, B. M., Laurienti, P. J., Norris, J., and Rejeski, W. J. (2014). Front. Psychol. 5:249. doi: $10.3389 /$ fpsyg.2014.00249

The article by Paolini and colleagues is a part of the Research Topic "The two-way link between eating behavior and brain metabolism" (Zilberter, 2015). The authors were first to report the effect of MR on brain networks during moderate hunger state. They used sophisticated analytical/experimental techniques and observed a new phenomenon, which they reported in a faultless manner. The main message is that a meal replacement (MR) curbs appetite and lowers functional connectivity (FC) in the regions of interest (ROI): insula, anterior cingulate cortex (ACC), superior temporal pole (STP), amygdala and hippocampus.

\section{OPEN ACCESS}

Edited by:

Miguel Alonso-Alonso,

Harvard Medical School, USA

Reviewed by:

Kyle S. Burger,

University of North Carolina at Chape

Hill, USA

Laura Nynke Van Der Laan, University Medical Center Utrecht,

Netherlands

*Correspondence:

Tanya Zilberter,

zilberter@gmail.com

Received: 16 January 2015 Accepted: 15 April 2015 Published: 28 April 2015

Citation:

Zilberter T (2015) Meal replacement and functional connectivity in the brain

network for appetite: connecting the dots. Front. Psychol. 6:547.

doi: 10.3389/fpsyg.2015.00547

\section{Meal replacemdents}

\section{Uses and Specifications}

MR is a formulation "containing ingredients which are expected to provide nourishment, nutrition, hydration, satisfaction of hunger/thirst, or desire for taste, texture or flavor" as defined by Health Canada (2010). The idea of MRs was first proposed in 1946 when J. L. Gamble from Harvard Medical School suggested the first recipe for a "life raft" survivor's kit (Gamble, 1989). As the era of spaceflight began, MR received much attention from nutritionists and food technologists.

Currently, besides medical formulas for specific health conditions including those requiring parenteral nutrition, MRs are adopted as a convenient tool in the battle against obesity (Hamdy et al., 2008; Wadden et al., 2009) and as such is chosen by the authors. Low compliance is considered to be the biggest obstacle for successful dieting and MR is shown to improve it, especially in the long run (Heymsfield et al., 2003; Wadden et al., 2009; Heymsfield, 2010). It is thought that this strategy works by increasing nutritional awareness, improving meal timing (Wing and Jeffery, 2001) or due to reduced energy content: MR is usually 2-3 times lower in calories than an average meal. Importantly, once a caloric deficit is created hours later, hunger is augmented (Paoli and coauthors demonstrated this as well) but food intake during the next meal is not increased. In the case of skipping breakfasts, for example, it resulted in a negative energy balance of about 400-kcal a day (Levitsky and Pacanowski, 2013).

The authors used a generic, commercial 240-Kcal MR beverage called BOOST, $98 \%$ of which consists of corn syrup, sugar, and milk protein. This particular MR successfully "calmed the hotstate brain network of appetite." It should not, however, be taken for granted that this MR is unique in eliciting the reported effect. MRs with increased viscosity (Zijlstra et al., 2008) decreased 
energy density (Murray et al., 2015) or improved nutrient composition (e.g., low-glycemic, protein-enriched, high in isoflavone, Berg et al., 2008; König et al., 2012) produced more favorable changes in long-term metabolic outcomes, such as improved insulin sensitivity and increased fat oxidation. On the other hand, using a MR containing carbohydrates instead of broadly used artificial sweeteners might indeed have a rewardrelated advantage: fMRI studies of oral stimulation (mouth rinsing without swallowing) with carbohydrates, both sweet and not sweet (maltodextrin), caused activation in some of the same ROI (e.g., the ACC as in Paolini et al., 2014), while stimulation with a non-carbohydrate sweetener indistinguishable by taste (saccharin) did not (Jeukendrup and Chambers, 2010) thus probably diminishing the hedonic/rewarding properties of noncarbohydrate MRs.

\section{Obesity}

Paolini and coauthors studied FC in older, obese adults and showed that after $2.5 \mathrm{~h}$ of food restraint, MR decreased cravings and hunger ratings, which was accompanied by reduced FC in the brain network for appetite (BNA). It is necessary to keep in mind that changes in FC after a MR in obese and non-obese subjects may be different: normal-weight subjects displayed less reduction of FC in the homeostatic, reward and emotion-related brain areas (Frank et al., 2014). Obese women comparing with non-obese exhibited greater fMRI-activation by food-related stimuli in a large number of brain regions involved with motivational effects of food including ACC, insula, hippocampus, and amygdala (Stoeckel et al., 2008). Visceral cues increased fMRI activation in the insula and decreased activation in amygdala among other regions in obese but not normal subjects (Tomasi et al., 2009).
One of comorbidities of obesity is anxiety (Singh, 2014) and subjects with anxiety are routinely excluded from the studies (García-García et al., 2013). Both lower sensitivity to reward and increased FC was shown to coexist in the ROI including the insula (Verdejo-García et al., 2015). Resting-state fMRI of patients with anxiety featured abnormalities in the ROI similar to Paolini and coauthors - in the amygdala, hippocampus, ventral striatum, insula, and ACC (Oathes et al., 2015). Resting-state brain activity is abnormal in anxiety (e.g., Dichter et al., 2015). While screening for schizophrenia, bipolar disorder, MS, Parkinson's, Alzheimer's, dementia, alcoholism, and binge eating, Paolini and coauthors did not exclude anxiety, thus the chance of an influence of this condition on the study outcome remains and should be kept in mind.

\section{Brain Network for Appetite}

Appetitive behavior is driven by a combined effort of sensory, gastric, and metabolic signals occurring after energy intake, which modulate taste activation in reward areas (Smeets et al., 2011). Paolini et al. emphasized the anatomically central location of the insula in the BNA, on the crossroad between lowerlevel representations and higher-level processing of visceral cues. Indeed, the insula is activated by gustatory sensing (van Rijn et al., 2015). Its connection with ACC provides the link between gustatory, emotional, cognitive, and behavioral processing (Jeukendrup and Chambers, 2010). PET data from hungry subjects exposed to real food vs. non-food stimuli (Wang et al., 2004) revealed activation in the insula, STP. They also registered activation in orbitofrontal cortex, which Paolini and coauthors did not expect to see due to lack of food cues processing in their protocol.

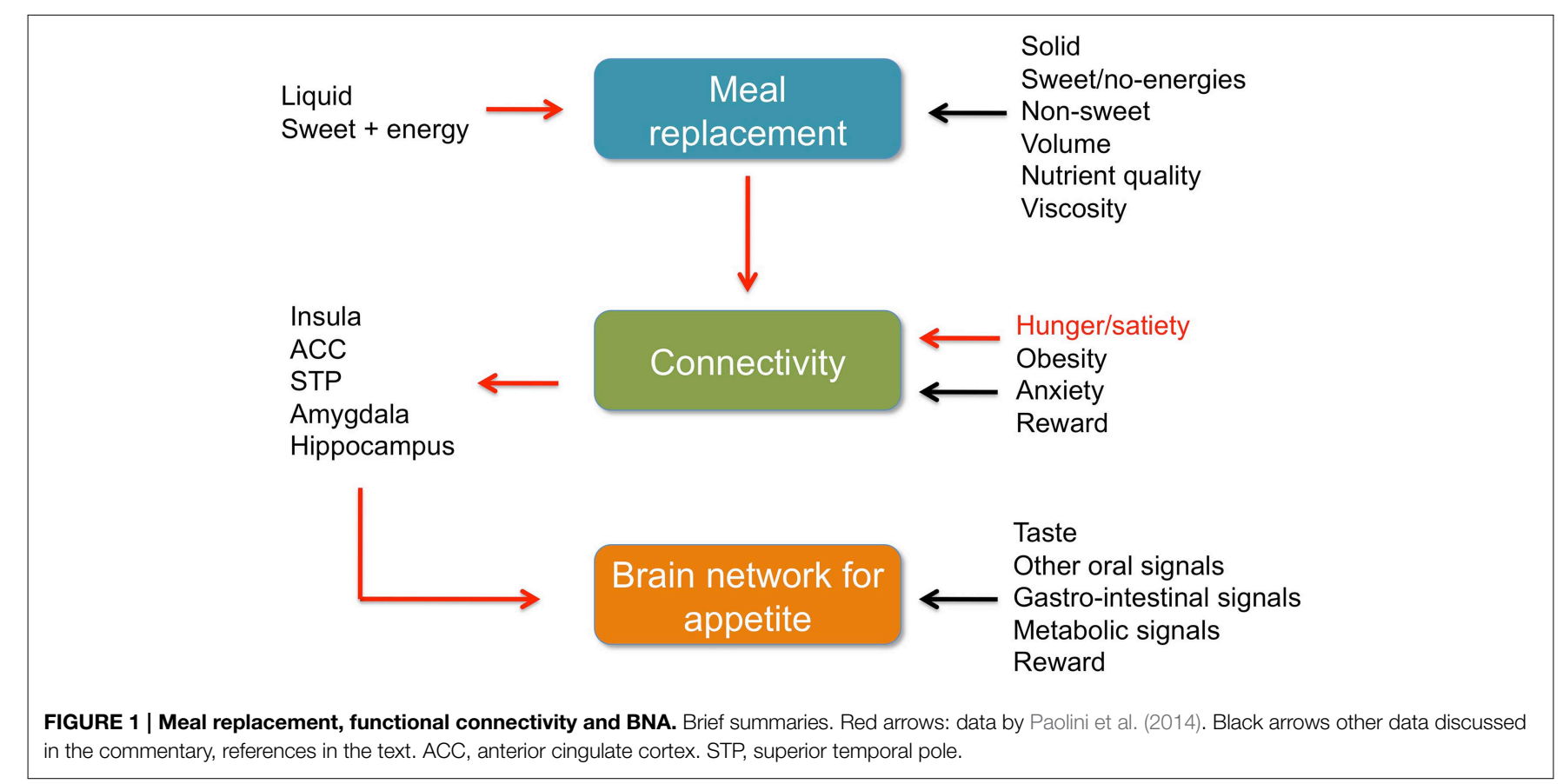




\section{Conclusion}

The accurate finding of Paolini and coauthors concern the vulnerable, growing population of overweigh/obese, aging men and women, free from neurological and neurodegenerative disorders and binge eating, not screened for the anxiety disorder. MR (liquid, carbohydrate-based, low-viscosity and low-fiber,

\section{References}

Berg, A., König, D., Deibert, P., Landmann, U., Frey, I., Kloock, B., et al. (2008). Favorable metabolic properties of a soy-honey-yoghurt product for meal replacement in overweight subjects with atherogenic risk. 77th Congr. Eur. Atherosclerosis Soc. 9, 253. doi: 10.1016/S1567-5688(08)71015-8

Dichter, G. S., Gibbs, D., and Smoski, M. J. (2015). A systematic review of relations between resting-state functional-MRI and treatment response in major depressive disorder. J. Affect. Disord. 172, 8-17. doi: 10.1016/j.jad.2014.09.028

Frank, S., Wilms, B., Veit, R., Ernst, B., Thurnheer, M., Kullmann, S. et al. (2014). Altered brain activity in severely obese women may recover after Roux-en Y gastric bypass surgery. Int. J. Obes. 38, 341-348. doi: 10.1038/ijo.2013.60

Gamble, J. L. (1989). Physiological information gained from studies on the life raft ration. Nutr. Rev. 47, 199-201. doi: 10.1111/j.1753-4887.1989.tb02838.x

García-García, I., Jurado, M. A., Garolera, M., Segura, B., Marques-Iturria, I., Pueyo, R., et al. (2013). Functional connectivity in obesity during reward processing. Neuroimage 66, 232-239. doi: 10.1016/j.neuroimage.2012.10.035

Hamdy, O., Goebel-Fabbri, A., Carver, C., Arathuzik, G., Shahar, J., Capelson, R., et al. (2008). Why WAIT program: a novel model for diabetes weight management in routine clinical practice. Obes. Manage. 4, 176-183. doi: 10.1089/obe.2008.0206

Health Canada. (2010). Classification of Products at the Food-Natural Health Product Interface: Products in Food Formats. Available online at: http://www. hc-sc.gc.ca

Heymsfield, S. B. (2010). Meal replacements and energy balance. Physiol. Behav. 100, 90-94. doi: 10.1016/j.physbeh.2010.02.010

Heymsfield, S. B., van Mierlo, C. A., van der Knaap, H. C., Heo, M., and Frier, H. I. (2003). Weight management using a meal replacement strategy: meta and pooling analysis from six studies. Int. J. Obes. 27, 537-549. doi: 10.1038/sj.ijo.0802258

Jeukendrup, A. E., and Chambers, E. S. (2010). Oral carbohydrate sensing and exercise performance. Curr. Opin. Clin. Nutr. Metab. Care 13, 447-451. doi: 10.1097/MCO.0b013e328339de83

König, D., Muser, K., Berg, A., and Deibert, P. (2012). Fuel selection and appetiteregulating hormones after intake of a soy protein-based meal replacement. Nutrition 28, 35-39. doi: 10.1016/j.nut.2011.02.008

Levitsky, D. A., and Pacanowski, C. R. (2013). Effect of skipping breakfast on subsequent energy intake. Physiol. Behav. 119, 9-16. doi: 10.1016/j.physbeh.2013.05.006

Murray, K., Placidi, E., Schuring, E. A., Hoad, C. L., Koppenol, W., Arnaudov, L. N., et al. (2015). Aerated drinks increase gastric volume and reduce appetite as assessed by MRI: a randomized, balanced, crossover trial. Am. J. Clin. Nutr. 101, 270-278. doi: 10.3945/ajcn.114.096974

Oathes, D. J., Patenaude, B., Schatzberg, A. F., and Etkin, A. (2015). Neurobiological signatures of anxiety and depression in resting-state functional magnetic resonance imaging. Biol. Psychiatry 77, 385-393. doi: 10.1016/j.biopsych.2014.08.006
240-Kcal) calmed the "hot-state brain network of appetite", which was activated by $2.5 \mathrm{~h}$ of food deprivation. It is important to further investigate whether or not the effect would be observed on young, lean, anxiety-free subjects, with this or other types of MR. The findings of Dr. Brielle Paolini and colleagues are thoughtprovoking and will definitely find a well-deserved place in the bigger picture of the appetite regulation mechanisms (Figure 1).

Paolini, B. M., Laurienti, P. J., Norris, J., and Rejeski, W. J. (2014). Meal replacement: calming the hot-state brain network of appetite. Front. Psychol. 5:249. doi: 10.3389/fpsyg.2014.00249

Singh, M. (2014). Mood, food, and obesity. Front. Psychol. 5:925. doi: 10.3389/fpsyg.2014.00925

Smeets, P. A., Weijzen, P., de Graaf, C., and Viergever, M. A. (2011). Consumption of caloric and non-caloric versions of a soft drink differentially affects brain activation during tasting. Neuroimage 54, 1367-1374. doi: 10.1016/j.neuroimage.2010.08.054

Stoeckel, L., Weller, R., Cook, E. W. III., Twieg, D., Knowlton, R., and Cox, J. (2008). Widespread reward-system activation in obese women in response to pictures of high-calorie foods. Neuroimage 41, 636-647. doi: 10.1016/j.neuroimage.2008.02.031

Tomasi, D., Wang, G., Wang, R., Backus, W., Geliebter, A., Telang, F., et al. (2009). Association of body mass and brain activation during gastric distention: implications for obesity. PLoS ONE 4:e6847. doi: 10.1371/journal.pone.0006847 van Rijn, I., de Graaf, C., and Smeets, P. A. (2015). Tasting calories differentially affects brain activation during hunger and satiety. Behav. Brain Res. 279, 139-147. doi: 10.1016/j.bbr.2014.11.019

Verdejo-García, A., Verdejo-Román, J., Rio-Valle, J. S., Lacomba, J. A., Lagos, F. M., and Soriano-Mas, C. (2015). Dysfunctional involvement of emotion and reward brain regions on social decision making in excess weight adolescents. Hum. Brain Mapp. 36, 226-237. doi: 10.1002/hbm.22625

Wadden, T. A., West, D. S., Neiberg, R. H., Wing, R. R., Ryan, D. H., Johnson, K. C., et al. (2009). One-year weight losses in the look AHEAD study: factors associated with success. Obesity 17, 713-722. doi: 10.1038/oby.2008.637

Wing, R. R., and Jeffery, R. W. (2001). Food provision as a strategy to promote weight loss. Obes. Res. 9, 271S-275S. doi: 10.1038/oby.2001.130

Wang, G. J., Volkow, N. D., Telang, F., Jayne, M., Ma, J., Rao, M., et al. (2004). Exposure to appetitive food stimuli markedly activates the human brain. Neuroimage 21, 1790-1797. doi: 10.1016/j.neuroimage.2003.11.026

Zijlstra, N., Mars, M., de Wijk, R. A., Westerterp-Plantenga, M. S., and de, G.C. (2008). The effect of viscosity on ad libitum food intake. Int. J. Obes. (Lond.) 32, 676-683. doi: 10.1038/sj.ijo.0803776

Zilberter, T. (2015). Appetite, reward, and obesity: the causes and consequences of eating behaviors. Front. Psychol. 6:411. doi: 10.3389/fpsyg.2015.0041

Conflict of Interest Statement: The authors declare that the research was conducted in the absence of any commercial or financial relationships that could be construed as a potential conflict of interest.

Copyright (c) 2015 Zilberter. This is an open-access article distributed under the terms of the Creative Commons Attribution License (CC BY). The use, distribution or reproduction in other forums is permitted, provided the original author(s) or licensor are credited and that the original publication in this journal is cited, in accordance with accepted academic practice. No use, distribution or reproduction is permitted which does not comply with these terms. 